\title{
Dietary Practices Adopted by Track-and-Field Athletes: Gluten-Free, Low FODMAP, Vegetarian, and Fasting
}

\author{
Dana M. Lis \\ University of California, Davis \\ Daniel Kings \\ Aspetar Qatar Orthopaedic and Sports Medicine Hospital \\ D. Enette Larson-Meyer \\ University of Wyoming
}

\begin{abstract}
Some track-and-field athletes implement special diets aiming to improve health and/or performance. An evidence-based approach to any diet is recommended to minimize the risks associated with unnecessary dietary restriction, which may potentially do more harm than good. Four prevalent diets are reviewed in this study: (a) gluten-free; (b) low fermentable oligosaccharides, disaccharides, monosaccharides, and polyols (FODMAP); (c) vegetarian; and (d) fasting diets. Recently, gluten-free diets and low FODMAP diets have emerged as novel regimes thought to improve gastrointestinal health and reduce the risk of exerciseassociated gastrointestinal symptoms. No direct beneficial outcomes have been associated with avoiding gluten for clinically healthy athletes. Indirectly, a gluten-free diet is associated with other dietary changes, particularly FODMAP reduction, which may improve adverse gastrointestinal symptoms. Vegetarian diets can optimally support athletic demands. However, attention is required to ensure adequate energy and intake of specific nutrients that are less abundant or less well absorbed from plant sources. Finally, fasting is a long-standing concept that is undertaken on a voluntary and obligatory basis. Despite limited supporting research, voluntary fasting is a popular alternative to conventional diets perceptually offering health and body composition benefits. Strict obligatory fasting guidelines likely require the implementation of tailored nutrition strategies to help athletes cope with athletic demands. Overall, a multitude of factors influence adherence to special diets. Even when adherence to a special diet is a necessity, education and advice from an accredited dietitian/nutritionist are recommended for track-and-field athletes to optimize nutrition for health and performance.
\end{abstract}

Keywords: diet, performance, special, sport

A variety of special diets are adopted by track-and-field athletes for a multitude of reasons. Gluten-free (GFD), vegetarian, and fasting diets are among the more prevalent diets adopted for health, ethical, religious, and performance purposes. A low fermentable oligosaccharides, disaccharides, monosaccharides, and polyols (FODMAP) diet is also gaining popularity as a beneficial strategy to reduce commonly occurring exercise-associated gastrointestinal symptoms (Costa et al., 2017). Due to the risks associated with unnecessary dietary restriction, special diets or dietary restraint should be carefully evaluated (Mountjoy et al., 2018). The following review will discuss the current state of knowledge, potential implications of select special diets, and practical considerations for implementation of these for trackand-field athletes aiming to optimize nutrition for health and performance.

Lis is with the Dept. of Neurobiology, Physiology, and Behavior, University of California, Davis, Davis, CA. Kings is with Aspetar Qatar Orthopaedic and Sports Medicine Hospital, Doha, Qatar. Larson-Meyer is with the Dept. of Family and Consumer Sciences, University of Wyoming, Laramie, WY. Address author correspondence to Dana M. Lis at dmlis@ucdavis.edu.

\section{Food Intolerances}

Track-and-field athletes with diagnosed food allergies or intolerances will require specialized dietary modifications to eliminate exposure to allergens or food that trigger symptoms. A foundational appreciation of these conditions is important to assess the necessity for adherence to a special diet and to sift through commonly reported coexisting food intolerances. Gluten intolerance has become one of the most popular self-reported reasons for a special diet, and therefore, attention will be focused on GFDs and FODMAP restriction in the following section.

\section{Food Allergies and Intolerances}

Adverse reactions to food are self-reported to occur in one fifth of the population; however, the origin of the reaction may differ (Turnbull et al., 2015). Variability in methodologies also challenges accurate evaluation of true allergy prevalence. Across the U.S. population, objective measures indicate food allergy prevalence rates to range between $\sim 2.5 \%$ and $3 \%$ (Rona et al., 2007; Turnbull et al., 2015). Observations from work in the field with athletes suggest that food intolerance appears to be escalating among athletes, yet numerous factors such as the use of 
nonvalidated food intolerance testing and self-reported incidence challenge accurate estimates of genuine intolerance (KosticVucicevic et al., 2016). Types of reactions to food can be classified into four primary categories: (a) immune mediated (e.g., egg, fish, nuts), (b) nonimmune mediated (common food triggers as immune mediated with different systemic response and subsequent symptoms), (c) exposure to toxin, and (d) genetic. A food allergy is defined as an adverse immune-mediated response, which occurs reproducibly upon exposure to a given food and absent when the food is avoided (Schafer et al., 2001). Other types of reactions are labeled intolerances, which are nonallergic food reactions (e.g., lactose deficiency) and thus do not involve the immune system (Schafer et al., 2001; Turnbull et al., 2015). Reactions to food can also transpire from toxin exposure or excess histamine in foods (e.g., spoiled fish) or from inborn metabolic errors such as in phenylketonuria (Turnbull et al., 2015). Finally, malabsorptive problems, such as fructose malabsorption or a disease condition, and functional gastrointestinal disorders may also be linked to food-related reactions.

\section{Common Food Allergies}

Immune-mediated food reactions can range in severity from minor abdominal discomfort to hives and to the most severe, anaphylaxis. Reactions generally develop within minutes of exposure. Investigation of allergen food reactions is less reviewed in adults than in adolescents; however, the most common food allergy triggers are shellfish, peanut, tree nuts, and fish, with some geographical variance (de Silva et al., 2014; Schafer et al., 2001). Cow's milk, egg, wheat, soy, peanut, tree nuts, fish, and shellfish allergies constitute the majority of food allergy reactions in younger populations (Rona et al., 2007). Determination of IgE-mediated reactions to food requires appropriate diagnosis beginning with a detailed medical/nutrition history to guide appropriate testing procedures (Platt \& Wulu, 2017). These verified diagnostic methods include skin prick, measuring food-specific IgE antibody levels, or the gold standard of double-blind placebo-controlled food challenges (Turnbull et al., 2015). Some inherent risks, confounding factors affecting results, arduous nature, and high costs are associated with these tests (Shtessel \& Tversky, 2018; Tapke et al., 2018). Subsequently, several alternative food intolerance tests appeal to athletes (e.g., microbiome testing, vega testing/ electrodermal, hair testing, applied kinesiology, serum-specific IgG, lymphocyte stimulation, facial thermography, gastric juice analysis, endoscopic allergen provocation, cytotoxicity assays, and the Mediator Release Test). Validation is lacking, and therefore, these alternative testing methods are not currently recommended. For track-and-field athletes, food avoidance based on dubious test results may introduce unnecessary food restriction and associated risks, which are discussed throughout this review. Established food allergy testing should be guided by a licensed medical specialist (e.g., allergist, immunologist), and indiscriminate testing for large batteries of allergens should be avoided (Turnbull et al., 2015).

\section{Common Food Intolerances/Malabsorption}

Given the ambiguous nature of food intolerances or malabsorption, there is a tendency for athletes to self-diagnose intolerances and subsequently restrict foods or food groups (Kostic-Vucicevic et al., 2016; Lis et al., 2015b). Lactose and fructose malabsorption, which result from insufficient enzyme and functional capability of transporter(s), respectively, are the most commonly reported food intolerances (Fedewa \& Rao, 2014; Levitt et al., 2013; Turnbull et al., 2015). Other food intolerances are less clear. Symptoms may appear hours to days after exposure (Turnbull et al., 2015) and range from gastrointestinal (e.g., abdominal bloating, loose stool, abdominal pain) to extraintestinal symptoms including fatigue, headaches, and cognitive difficulties. Several of these symptoms overlap with those characterizing irritable bowel syndrome, functional gastrointestinal disorders, or exercise-induced gastrointestinal syndrome (Costa et al., 2017; Turnbull et al., 2015). Emerging work in this area questions the potential for repeated stress on the gut and associated physiological alterations associated with exercise-induced gastrointestinal syndrome to increase susceptibility to dietary triggers or the development of chronic gastrointestinal disease (Colbey et al., 2018; Costa et al., 2017).

\section{Gluten-Free Diets}

\section{GFD Adherence}

Adherence to a GFD has exploded in popularity among athletes. Forty-one percent of nonceliac athletes report adhering to a GFD at least half of the time with $\sim 60 \%$ self-reporting "gluten intolerance" (Lis et al., 2015b). A strict GFD eliminates all sources of gluten, a storage protein composite, with the alcohol-soluble gliadins defined as prolamins and the alcohol-insoluble glutenins as glutelins. Gliadin is incompletely digested, excreted, and does not trigger an immunological response in individuals without celiac disease. It is well established that a GFD is essential in managing health and symptoms in individuals with clinical conditions such as celiac disease, wheat allergy, and genuine nonceliac gluten/wheat sensitivity. Nonetheless, the number of athletes reported to follow a GFD appears to be four-fold higher than those of the general population who are estimated to clinically require gluten elimination (Sapone et al., 2012). A primary reason for adherence to a GFD in athletes is the widespread conviction that gluten elicits universal gastrointestinal injury/symptoms and triggers inflammation. A GFD is further touted as overall healthier and suggested to provide an ergogenic advantage (Lis et al., 2015b). Only one study has examined the effects of a GFD in nonceliac endurance athletes (Lis et al., 2015a). In this tightly controlled randomized, crossover, doubleblind study, athletes followed a short-term gluten-containing diet versus GFD. Diet and exercise were replicated in both trials, but no differences in measures of gastrointestinal injury, gastrointestinal symptoms, systemic inflammatory responses, perceptual well-being, or exercise performance were observed between the diets. Only anecdotal-type substantiation supports the efficacy of a GFD for clinically healthy athletes. Nonetheless, it is important to understand the unique stress placed on the gut in some track-andfield athletes and the likely higher incidence of exercise-induced gastrointestinal syndrome (Costa et al., 2017; van Wijck et al., 2012). Potential exists for compromised gastrointestinal integrity and function to increase the incidence or magnitude of gastrointestinal-related food symptoms or gastrointestinal disorders (Costa et al., 2017).

\section{Gluten to FODMAPs Link}

Adverse reactions, particularly gastrointestinal symptoms, are associated with consumption of gluten-containing foods in individuals without a clinical condition requiring gluten elimination (Biesiekierski \& Iven, 2015). Amid subjective reports of a GFD improving gastrointestinal symptoms, an interesting connection 
exists between reduced FODMAP intake (e.g., fructans) and avoidance of gluten-containing grains (Gibson \& Muir, 2013; Gibson et al., 2015; Skodje et al., 2018). A reduction in FODMAPs has been recognized as a modulating factor for symptom improvement with a GFD and not gluten itself (Skodje et al., 2018). Wheatbased food products such as breads and cereals not only contain gluten but are also rich in fructans, which are within the FODMAPs family and poorly digested (Biesiekierski \& Iven, 2015; Fedewa \& Rao, 2014). This concept is strongly supported by a handful of clinical studies and scientific editorials detailing that the subsequent reduction in FODMAP intake is accountable for improvements in gastrointestinal symptoms and that fructans rather than gluten are associated with gastrointestinal symptom improvement in the majority of individuals with self-reported nonceliac gluten sensitivity (Biesiekierski \& Iven, 2015).

\section{FODMAP Mechanisms}

FODMAPs are a family of fermentable short-chain carbohydrates found in a wide assortment of foods/food constituents (Staudacher et al., 2017). Select high FODMAP foods common in an athlete's diet are categorized in Table 1 alongside low FODMAP exchanges (Lis et al., 2016b). Briefly, a low FODMAP diet is an individualized nutrition strategy with three phases (i. low FODMAP, ii. rechallenge, and iii. personalization phases) to tailor reduced intake of specific short-chain carbohydrates that can elicit symptoms. This diet has emerged as a frontline treatment for symptoms of irritable bowel syndrome with a $70 \%$ success rate (Staudacher et al., 2017). Within a healthy general population, some FODMAPs are poorly digested, but the resulting gastrointestinal symptoms are nonexistent or trivial (Ong et al., 2010). Conversely, in athletes undertaking strenuous exercise with a subsequent impairment of gastrointestinal function and integrity (i.e., transporters), undigested food molecules may increase the osmotic load in the small intestine and contribute to increased osmotic water translocation, volume, and physiological consequences such as loose stool or diarrhea (Staudacher et al., 2014; van Wijck et al., 2012). Upon transit to the lower intestine, these malabsorbed and highly fermentable carbohydrates reach the colon and are subject to bacterial fermentation (breakdown) and result in physiological consequences such as increased luminal volume and pressure (e.g., hydrogen, methane, hydrogen sulfide). In addition, FODMAP intake could augment gastrointestinal symptoms (e.g., abdominal bloating and discomfort, excessive flatulence, urge to defecate, alterations in bowel movements) initiated by the osmotic effects of high carbohydrate consumption necessary to support fueling demands (Pfeiffer et al., 2012).

FODMAP research has predominantly concentrated on lower gastrointestinal symptoms (e.g., abdominal bloating, flatulence, abdominal pain, cramping, diarrhea/loose stool). However, FODMAPs also influence upper gastrointestinal symptoms, such as feeling of fullness, as demonstrated in a clinical feeding study that administered doses of fructose and glucose via gastric infusion (Masuy et al., 2018). Costa et al. (2017) has further summarized that upper gastrointestinal symptoms may be linked to the ileal break feedback mechanism, inhibitory or not. Upper and lower gastrointestinal symptoms may be affected by FODMAPs, but these nonspecific symptoms also congruently manifest from mechanical, physiological, and other nutritional factors (Costa et al., 2017). FODMAPs may not be an exclusive gastrointestinal symptom trigger but amplify symptoms initiated by other factors.

\section{Low FODMAP Strategies for Track-and-Field Athletes}

Athlete-specific data support the concept of FODMAPs affecting exercise-associated gastrointestinal symptoms (Lis et al., 2016a, 2017). Many athletes already self-eliminate foods high in FODMAPs but may not distinguish that these foods are in the FODMAP family (Lis et al., 2016b). Lactose-containing foods are the most frequently eliminated, followed by fructose in excess of glucose, galacto-oligosaccharides, polyols, and fructans. Two case study reports and one published intervention study further encourage the use of a low FODMAP diet compared with habitual diet (typically high in FODMAPs) to reduce the severity gastrointestinal symptoms during and also outside of exercise (Gaskell \& Costa, 2018; Lis et al., 2016a, 2017). Importantly, gastrointestinal symptoms may transpire after a strenuous training session/race potentially affecting refueling for subsequent events. This is of concern in some track-and-field events where competition is carried over multiple days and/or multiple times per day. Assessment of FODMAP intake may be required before, during, and after exercise to optimize gastrointestinal contentment and refueling.

\section{Nutritional Considerations for GFD and Low FODMAP Diet}

Any dietary treatment should be guided by appropriate diagnosis and dietary/medical management to minimize the risks associated with overlooking the underlying cause(s) and the risks associated

\section{Table 1 High FODMAP Foods Commonly Consumed in an Athlete's Diet}

\begin{tabular}{|c|c|c|}
\hline FODMAP categories & High FODMAP foods & Low FODMAP food exchanges \\
\hline High lactose & Yogurt, cow's milk & Lactose-free milk, and soy milk (from soy protein) \\
\hline Excess fructose & $\begin{array}{l}\text { Apples, figs, watermelon, cherries, agave, honey, many } \\
\text { fruit juices (e.g., apple, orange), and beetroot }\end{array}$ & $\begin{array}{l}\text { Oranges, berries, banana, grapes, kiwi fruit, cantaloupe, } \\
\text { strawberry, blueberries, raspberries, fruit juices }{ }^{\mathrm{a}} \text { made } \\
\text { from the above low FODMAP fruits, blended vegetable } \\
\text { juice with tomato base, and canned or pickled beets }\end{array}$ \\
\hline High fructans/GOS & $\begin{array}{l}\text { Dates, dried apricots, cashews/pistachio nuts, breads/ } \\
\text { bagels, onions, wheat-based energy bars, and ripe } \\
\text { banana }\end{array}$ & $\begin{array}{l}\text { Gluten-free, spelt, special sourdough spelt breads, rice } \\
\text { cakes, corn tortillas, wheat and/or gluten-free energy } \\
\text { bars, and unripe banana }\end{array}$ \\
\hline High polyols & $\begin{array}{l}\text { Dried apricots, protein bars and powders, some elec- } \\
\text { trolyte tablets, and sugar-free gum/candies }\end{array}$ & $\begin{array}{l}\text { Protein bars with alternative sweeteners, limit intake of } \\
\text { sugar-free gum/candies, or choose sugar-containing brands }\end{array}$ \\
\hline
\end{tabular}

Note. Check cereals, bars, sports foods, mixed beverages, and mixed meals for high FODMAP ingredients. FODMAP = fermentable oligosaccharides, disaccharides, monosaccharides, and polyols; GOS, galacto-oligosaccharides.

${ }^{a}$ Depending on the types and blend, fruit juices can be high in excess fructose and therefore problematic for some athletes (especially when ingested in high amounts). 
with unnecessary food restriction (Cialdella-Kam et al., 2016; Hill et al., 2017; Shepherd \& Gibson, 2013). Numerous benefits are publicized with GFD and low FODMAP diets, yet these special diets are also associated with perturbations in healthy gut microbiota, short-chain fatty acid production, possible increased arsenic intake (Bulka et al., 2017; Halmos et al., 2015), orthorexia nervosa and disordered eating, increased psychosocial anxiety, and compromised energy/nutrient intake (Hill et al., 2017; Staudacher et al., 2017). Historically, a GFD has also been associated with suboptimal intake of iron, B vitamins, and protein and higher intake of sugar and fat. With significant improvements in commercially available gluten-free foods, this issue is less concerning (in Westernized countries). Although the exponential growth in the glutenfree market seems to be tapering, market reports suggest the low FODMAP diet to be the next popular special diet for athletes. Keeping this in mind, the primary goals of implementing a GFD or low FODMAP diet to manage gastrointestinal symptoms should be to establish underlying mechanisms and to minimize unnecessary food restriction and the associated psychosocial/nutritional risks. A registered dietitian specializing in sports nutrition and certified in low FODMAP diet teaching (Hill et al., 2017) should be consulted. Overall, to address the multifactorial nature of gastrointestinal symptoms, emerging evidence undoubtedly supports a beneficial role of FODMAP reduction as part of a treatment plan for some athletes with exercise-induced gastrointestinal syndrome (Costa et al., 2017; Lis et al., 2017).

\section{Vegetarian and Vegan Eating}

Track-and-field athletes adopt vegetarian and vegan diets for health, ethical, environmental, religious/spiritual, and aesthetic reasons (Table 2). Although interest in plant-based diets among athletes is not new, their popularity, particularly for vegan diets and semivegetarian or flexitarian diets, seems to be increasing with considerable variability by country, sport, and current public trends (Meyer \& Reguant-Closa, 2017). Prevalence rates of vegetarianism among athletes are not well established but are assumed to be similar to that of the general population. Recent statistics suggest that $22 \%$ of the world population is vegetarian (Leahy et al., 2010). The only published study in elite athletes indicated that $8 \%$ of international athletes followed a vegetarian diet-1\% being vegan (Pelly \& Burkhart, 2014).

Although concern exists about the adequacy of vegetarian diets for track-and-field athletes, it is well established that vegetarian diets can be nutritionally adequate to support training demands provided a variety of plant foods and source of vitamin B12 (Agnoli et al., 2017) are sufficiently consumed. Hence, appropriate nutrition education is encouraged for track-and-field athletes.

\section{Potential Benefits of Vegetarian Diets}

Plant-based diets may offer health advantages over the typical Western diet. Vegetarian and vegan diets are associated with a reduced risk for chronic diseases in nonathletic populations (Melina et al., 2016). Less is known about the ability of these diets to enhance athletic performance (Craddock et al., 2016). A recent review of observational and short-term intervention studies found no benefit or detriment to strength/power, aerobic or anaerobic performance parameters as a result of consuming a vegetarian rather than a nonvegetarian diet for up to 12 weeks (Craddock et al., 2016). Due to the naturally high carbohydrate content, a vegetarian diet may be advantageous for fueling

\section{Table 2 Types of Vegetarian Diets}

\begin{tabular}{ll}
\hline Vegan (strict vegetarian) & $\begin{array}{l}\text { Excludes all animal products including } \\
\text { dairy and eggs and honey } \\
\text { Avoids all flesh foods; may or may not } \\
\text { consume eggs or dairy products }\end{array}$ \\
Vegetarian & $\begin{array}{l}\text { Includes milk or other dairy products } \\
\text { but not eggs or other animal foods }\end{array}$ \\
Lacto-vegetarian & $\begin{array}{l}\text { Includes eggs but not dairy products } \\
\text { Includes eggs and dairy products }\end{array}$ \\
\hline
\end{tabular}

Note. Athletes who periodically eat small amounts of fish (pesco-vegetarian) and chicken (pollo-vegetarian), who typically eat a meatless diet but occasionally include meat or fish (flexitarian), or who try to limit red and other meats (semivegetarian) are often included in vegetarian classifications.

(Craddock et al., 2016). In addition, antioxidant and phytochemicals (Trapp et al., 2010) and the possibility of slight serum alkalinity may be advantageous; however, this has yet to be shown to augment athletic performance (Applegate et al., 2017; Trapp et al., 2010).

\section{Vegetarian Nutrient Considerations and Recommendations}

To ensure optimal health and performance, track-and-field athletes following vegetarian diets should select a wide variety of minimally processed vegetables, fruits, grains, nuts, seeds, legumes, and soy products and ensure adequate energy intake (Melina et al., 2016). Adopting a vegetarian diet may result in a reduction of energy intake or of specific nutrients including omega-3 fatty acids, iron, zinc, calcium, vitamin D, iodine, and vitamin B12. These nutrients are less abundant in plant foods or are less well absorbed from plant compared with animal sources.

\section{Energy in Vegetarian Track-and-Field Athletes}

Meeting but not exceeding energy needs is a foundation of sports nutrition. Difficulty in meeting energy requirements on a vegetarian diet may be due to food choices that are excessively high in fiber or of low energy density some track-and-field athletes are poorly prepared to make healthy vegetarian choices at work, school, training, and when traveling. This can result in undereating or the selection of less nutrient-dense food. Aiming for five to eight meals/ snacks per day and adequate planning may help athletes meet energy needs. As appropriate, track-and-field athletes can increase energy intake by selecting energy-dense foods and by reducing fiber-rich foods. It is also important to note that a vegetarian diet may be used by some track-and-field athletes to mask restrictive eating or an eating disorder (Cialdella-Kam et al., 2016).

\section{Macronutrients: Protein, Carbohydrate, and Fat}

A common misconception is that vegetarian track-and-field athletes will not consume adequate protein. Meeting even the higher protein requirements of athletes and additional need for adolescent athletes is not typically a concern provided adequate energy and a variety of high-protein foods are consumed (Castell et al., 2018; Melina et al., 2016) (Table 3). As previously believed, it is unnecessary to combine plant foods in the same meal but instead eat a variety of protein-containing foods throughout the day (Marsh et al., 2013). Protein requirements in a diet consisting exclusively 


\section{Table 3 Vegetarian Sources of Key Nutrients}

\begin{tabular}{|c|c|}
\hline Protein & $\begin{array}{l}\text { Beans, peas, lentils, soy products, nuts and nut } \\
\text { butters, dairy products, and most soy/plant-based } \\
\text { "milks" }\end{array}$ \\
\hline Healthy fats & Nuts, seeds, nut butters, avocado, and olive oil \\
\hline Omega-3 fatty acids & $\begin{array}{l}\text { Walnuts, flax, chia, camelina, and hemp seeds } \\
\text { and oils }\end{array}$ \\
\hline Iron $^{a}$ & $\begin{array}{l}\text { Beans, peas, lentils, edamame, nuts, seeds, } \\
\text { many grain products, fortified bread, and } \\
\text { breakfast cereals }\end{array}$ \\
\hline Zinc $^{\mathrm{a}}$ & Beans, peas, lentils, edamame, nuts, and seeds \\
\hline Calcium & $\begin{array}{l}\text { Excellent bioavailability }(>50 \%) \text { : Chinese cab- } \\
\text { bages, kale, texturized vegetable proteins; } \\
\text { average bioavailability }(\sim 30 \%) \text { : dairy products } \\
\text { and calcium-set tofu; lower bioavailability: } \\
\text { fortified soymilk, most nuts, seeds, and beans }\end{array}$ \\
\hline Vitamin D & $\begin{array}{l}\text { Fatty fish, vitamin D-fortified cereals, marga- } \\
\text { rine, and plant-based "milks" }\end{array}$ \\
\hline Iodine & Iodized salt, seaweed, dairy products, and eggs \\
\hline Vitamin B12 & $\begin{array}{l}\text { Nutritional yeast, soymilk and plant-based } \\
\text { "milks," fortified meat analogs, and Shiitake } \\
\text { mushrooms }\end{array}$ \\
\hline
\end{tabular}

${ }^{a}$ Absorption enhanced by organic acids, including vitamin C (see Melina et al., 2016 and Otten et al., 2006, for additional food sources).

of less well-digested plant sources, such as whole legumes and unprocessed grains versus well-digested sources including soy, dairy, or egg protein, may be slightly elevated to account for the lower amino acid digestibility (Otten et al., 2006). Finally, it is suggested that resting creatine and carnitine concentrations, which are predominately present in meat, may be lower in vegetarians and supplementation may be warranted (Larson-Meyer, 2018).

Carbohydrates are an important fuel source and should make up the bulk of most athletes diets. However, the challenge for many track-and-field athletes, vegetarian or not, is obtaining carbohydrates from high-quality whole food sources, such as whole grains, quinoa, and starchy vegetables, rather than from overly processed carbohydrates and simple sugars.

Fat is also an integral component to the athlete's diet. It is specifically important to ensure adequate intake of plant-based sources of omega-3 fatty acids through selection of omega-3-rich foods (Table 3) and replacing omega-6-rich oils (Jeromson et al., 2015). Omega-3 fatty acids may aid in the inflammatory modulation, whereas maintaining a low ratio of omega-6 (e.g., nuts, seed oils soy, sunflower, safflower) to omega-3 fatty acids allows for better elongation of plant-based omega- 3 fatty acids (eicosapentaenoic acid and docosahexaenoic acid). In additionally, docosahexaenoic acid-rich microalgae supplements may be of interest to vegetarian athletes (Melina et al., 2016).

\section{Micronutrients}

A well-balanced vegetarian diet provides an abundance of nutrients including vitamins A, C, E, and K; folate; potassium; and magnesium (Melina et al., 2016). Depending on food choices, however, meeting daily requirements for iron, zinc, calcium, and vitamin B12 may be challenging. Iron and zinc are important for optimal performance and growth. Compromised iron status has been found in semivegetarian athletes and lacto-ovo vegetarian athletes compared with omnivorous controls (Castell et al., 2018). This is a particular concern for distance and endurance athlete (marathon and race walking) who may be more vulnerable. Although vegetarian track-and-field athletes can achieve adequate iron and zinc status by selecting foods rich in these nutrients (Table 3), knowledge about iron- and zinc-rich food inclusion and the factors that enhance/impair absorption is essential (Gilani et al., 2005; Melina et al., 2016). High-dose supplementation of both minerals can impair immune function and the absorption of other minerals, and therefore, high-dose supplementation is not recommended unless deficiency is present (Maughan et al., 2018).

Calcium, integral for bone health, is a concern for vegan trackand-field athletes and vegetarians who consume little to no dairy or vegetarian milks not fortified in dietary calcium. Opting for nondairy, well-absorbed calcium-containing foods (listed in Table 3) is preferred over calcium supplements (Melina et al., 2016). The calcium bioavailability of most of these plant foods is as equivalent to cow's milk. Calcium from spinach, chard, beet greens, and rhubarb, however, is of low bioavailability $(<5 \%)$ due to high oxalate content. Fortified foods, calcium-rich mineral water, or calcium supplements if necessary are also options. Vitamin D, which aids in calcium absorption, may also be deficient due to reduced intake of fatty fish, vitamin-D-fortified dairy products, and limited sun exposure (particularly during indoor training seasons). Requirements can be met by spending 530 min (depending on fair or dark skin) outside, at close to solar noon several times per week during the summer (Table 3; Owens et al., 2018). Vitamin D3, derived from lichen, or D2, produced from irradiation of ergosterol from yeast, are vegan sources, but vitamin D3 may be more effective at increasing vitamin D status.

Iodine is a red flag mineral for many vegans and vegetarians who avoid table salt (typically fortified with iodine), limit cow's milk consumption, or consume plant foods grown in iodinepoor soil (e.g., parts of the United Kingdom, United States, and New Zealand; Krajcovicova-Kudlackova et al., 2003). Although many plant foods such as cruciferous vegetables, sweet potatoes, and soybeans naturally contain "goitrogens," which impair the synthesis of thyroid hormone, their consumption does not decrease thyroid sufficiency unless iodine status is also compromised (Messina \& Redmond, 2006). Finally, vitamin B12 is a concern for vegan and semivegan athletes because it is found exclusively in animal products. Vegan track-and-field athletes should consume vitamin B12-fortified foods daily or take a vitamin B12-containing supplement or multivitamin. Vegetarian track-and-field athletes should consider taking a supplemental source if their intake of dairy products and/or eggs is limited. Athletes should also be aware that some dietary supplements may come from animal sources including gelatin, collagen, omega-3 fatty acids, and vitamin D3.

Overall, vegetarian and vegan diets that contain a variety of whole grains, vegetables, fruits, legumes, nuts, and seeds can provide the protein, carbohydrate, fat, vitamins, and minerals required for track-and-field athletes. Depending on dietary choice, emphasis of foods high in protein, iron, zinc, calcium, and vitamin B12 (e.g., yeast extract products) will ensure adequate nutrient status. Although research strongly suggests that a plant-based diet may offer some health benefits, there is little evidence that vegetarian diets are superior to omnivorous diets for improving athletic training, health, or performance.

\section{Fasting Diets}

Fasting is characterized by the absence of energy intake for sustained period of time ranging from several hours to days 
(Maughan et al., 2010). It is not a new concept, but an age-old practice prescribed by many religions (Trepanowski \& Bloomer, 2010). Apart from religious obligation, fasting also holds appeal for weight loss, chronic disease management, and to increase longevity (Horne et al., 2008). However, the impacts of fasting, particularly for track-and-field athletes, are inconclusive and challenging to translate into practice due to methodological variances, study design limitations, animal-based concepts, and diverse clinical populations.

Recently, fasting has received an upsurge of attention. Some forms of fasting are promoted as a strategy to offer health and performance benefits. This has prompted an increase in contemporary fasting publications and renewed academic focus, which has provided some insight into the possible effects of fasting on athletic performance. In particular, investigation of the use of fasting to enhance substrate utilization and mitochondrial adaptation to enhance exercise metabolism and performance (Aird et al., 2018). Any improvements in lipid profile, inflammatory markers, glucose metabolism, or cardiovascular function are short-lived and are not clinically significant (Barkia et al., 2011; Memari et al., 2011; Stockman et al., 2018). These findings prevent using nonobligatory fasting practices within standard practice evidencebased recommendations.

\section{Types of Fasting Practices}

Several types of fasting exist. Intermittent fasting (IF) and caloric restriction are the most predominate. IF is conducted intermittently with fast and refeed periods each 24-hour day. Caloric restriction is a chronic reduction in calories for a prolonged period of time where ad libitum water is permitted. Most applicable literature has focused on IF, and therefore, the following discussion will focus on this type of fasting. IF is subdivided into three categories: alternate day fasting, whole-day or periodic fasting, and timerestricted fasting (TRF). In all cases, a primary concern for trackand-field athletes is the loss of lean mass during a period of fasting or caloric restriction (Heilbronn et al., 2005).

Time-restricted fasting has received the most attention within the fasting literature. This form of fasting theoretically offers metabolic and body composition benefits for athletes (Morton et al., 2018). It involves 16-20 hr of fasting with a 4- to 8-hr feeding window. Several commercial variations of this diet have been developed. To date, only one study in recreationally active and resistance-trained athletes has been conducted. Findings indicate TRF does not support favorable changes in lean and fat mass compared with a normal diet (Tinsley et al., 2017). These observations may be attributed to unmatched macronutrient intake, specifically protein, between the normal diet group $(1.4 \mathrm{~g} / \mathrm{kg})$ compared with the TRF group $(1.0 \mathrm{~g} / \mathrm{kg})$. A follow-up study matching protein intakes $(1.9 \mathrm{~g} / \mathrm{kg}$ in both groups) demonstrated that TRF may be more effective in reducing fat mass while maintaining lean mass compared with normal diet controls (Moro et al., 2016). However, these results could be influenced by the more favorable feeding period around the training period for the TRF group.

\section{Ramadan IF}

Ramadan is a holy month during which Muslims refrain from eating and drinking between sunrise and sunset for 30 days. It is the most widely studied form of TRF and probably the most relevant for many elite athletes. Depending on the seasonal and geographical conditions, Ramadan falls on different dates every year and fasting varies from 11 to 18 hours daily (Azizi, 2002); patterns that can indirectly affect performance and alertness (Roky et al., 2004). Ramadan is also associated with more rapid onset of fatigue, lethargy, and noncontact athlete injury (Chtourou et al., 2011; Tian et al., 2011). Therefore, much research has focused on the factors negatively affecting performance and tools to mitigate these potential detriments (Tables 4 and 5).

\section{Nutrition and Ramadan}

Daily eating routines are characterized by two meals: one before sunrise (Sahur) and one after sunset (Iftar). Variation in Ramadan food volume and eating patterns as well as fundamental nutrition

\section{Table 4 Factors Involved in Detrimental Effects on Physical Performance During Ramadan}

- Training time of day

- Geographical location (and if the environment is controlled)

- Levels of athlete education and fasting experience

- Circadian rhythms

- Changes in sleep pattern (architecture and duration)

- Physiological, metabolic, and hormonal changes

- Blood glucose level reduction

- Reduced daytime fluid intake

- Decrease in body temperature

- Alteration in psychomotor functioning (deterioration across the day)

- More rapid onset of fatigue

- Possible increase risk of injury and the effect on training load

Note. Adapted from Farooq (2016).

\section{Table 5 Select Strategies to Cope With Ramadan Fasting for Track-and-Field Athletes}

\begin{tabular}{|c|c|}
\hline Focus & Strategy description \\
\hline Training & $\begin{array}{l}\text { a. Shift training to morning and evening to maintain } \\
\text { effective training load } \\
\text { b. Monitor "well-being" (e.g., pre- and postsession fatigue, } \\
\text { hydration status) and adjust training load appropriately } \\
\text { c. Promote rest (i.e., naps) after morning training } \\
\text { d. Music may counteract negative effects } \\
\text { e. Sports psychology support to address anxiety issues } \\
\text { regarding ability to maintain performance }\end{array}$ \\
\hline Education & $\begin{array}{l}\text { a. Prior education on key areas (e.g., behavioral adaptation } \\
\text { to minimize fluid loss) } \\
\text { b. Advice on portion size control (for the Iftar meal) } \\
\text { c. Query beliefs and individualize nutrition plans to cope } \\
\text { with Ramadan }\end{array}$ \\
\hline Nutrition & $\begin{array}{l}\text { a. Focus on protein quality and intake amount to maintain } \\
\text { lean mass } \\
\text { b. Encourage carbohydrate at meals } \\
\text { c. Electrolyte/oral rehydration solutions as needed to } \\
\text { maintain hydration status } \\
\text { d. Carbohydrate mouth rinsing as appropriate to maintain } \\
\text { performance } \\
\text { e. Individualized fluid/nutrition strategies adapted for un- } \\
\text { ique logistical considerations } \\
\text { f. Quick communication technologies useful to guide/ } \\
\text { monitor dietary intake } \\
\text { g. Dietary supplements (e.g., creatine, beta alanine) for } \\
\text { performance-focused interventions } \\
\text { h. Promote good oral health care across the refeed window }\end{array}$ \\
\hline
\end{tabular}


challenges have been previously characterized (Reilly \& Waterhouse, 2007). The two main challenges are that foods offered tend to be higher in fat and sugar compared with habitual diets and that meal quality is less under an athlete's full control due to the social nature of the eating occasion. It is commonly believed that Ramadan fasting results in a significant calorie deficit. However, studies have demonstrated that energy intake is similar to nonfasting periods but that eating times are later/earlier and within a limited time frame (Maughan et al., 2010). Amid eating challenges, the primary goal for track-and-field athletes should be to maintain body composition as well as minimize decrements in performance. Due to the variances in food availability, there is potential to overeat at fewer meal times, and it can be difficult for some athletes to maintain a stable body composition. Conversely, for some athletes, food choices during Ramadan may become better planned, and subsequently, the quality of food is improved compared with intake during the rest of the nonfasting year. Demonstrating this, unexpected improvements in lean mass and fat mass have even been measured, which may be attributed to improved food choices during Ramadan (Fahrial Syam et al., 2016; Norouzy et al., 2013). Particularly, during the first week of fasting, body composition measures may be inadvertently skewed by increased total body water loss, decreased gastrointestinal volume, and glycogen stores. These factors should be considered with athlete monitoring during this fasting period.

\section{Unique Sport Nutrition Challenges}

Ramadan is an opportunity to offer education opportunities to track-and-field athletes during a period when an athletes' receptiveness may be enhanced with a renewed interest in well-being or to maintain physical capacity throughout fasting. For the sports nutrition practitioner, several well-documented challenges before, during, and after exercise exist. Rehydration, posttraining recovery, fatigue management, portion control, and maintaining optimal body composition are the most common nutrition challenges (Table 4; Norouzy et al., 2013). These challenges are magnified when Ramadan occurs across major sporting events (e.g., the Olympics, the FIFA World Cup). Competing in a non-Muslim country and requirements of weight-making sports present further complications (Aloui et al., 2016). Muslim track-and-field athletes undertaking obligatory fasting are also at a potential disadvantage compared with voluntary fasting as they are less able to modify their feeding periods around training. Some athletes will obtain special permission to observe their fast after an important event. In addition, valuable nutrition strategies such as carbohydrate mouth rinsing may be not permitted due to the interpretation of fasting law by Islamic scholars. Overall, many challenges are associated with Ramadan fasting, and individualized strategies are required for successful management to avoid a possible detraining effect (Table 5; Aloui et al., 2016; Maughan et al., 2012).

\section{Knowledge and Beliefs}

A solid understanding of the knowledge and beliefs pertaining to Ramadan is important for practitioners counseling Muslim trackand-field athletes as much contradictory evidence exists on the effects of Ramadan fasting on health. Personalized knowledge and beliefs can often translate into attitudes and practices. Longstanding experiences established in early years, advice from peers, knowledge level, and how well the environment is controlled appear to be significant factors of Ramadan impacting performance
(Chamari et al., 2016). It is commonly trusted that Ramadan fasting negatively affects physical performance (Chamari et al., 2016). However, evidence continues to advocate that only a few aspects of physical fitness are negatively affected by Ramadan (Alkandari et al., 2012; Chamari et al., 2016). Cognitive performance (e.g., psychomotor function, vigilance, executive function) and decision making are negatively impacted, which may moderately compromise skill execution and reaction time in some sports (Kirkendall et al., 2012; Meckel et al., 2008). Overall, maintenance of daily energy and macronutrient intakes, body composition, training load, and sleep duration similar to the rest of the year will minimize impairments of physical performance during Ramadan.

Evidence is lacking to support any benefit of fasting compared with conventional techniques for improving body composition or metabolic parameters in track-and-field athletes. Nutrition strategies should be planned in advance to avoid possible performance decrements during obligatory fasting.

\section{Conclusions}

Special diets may be appropriate for some track-and-field athletes, but each of these should be carefully evaluated as well as the rationale for choosing a diet. Ad hoc adherence to a special diet is associated with several risks, which should be carefully evaluated and monitored. Even in cases where a special diet is necessary, proper education is essential as dietary restriction may do more harm than good. To optimize nutrition for elite performance guidance from an accredited dietitian/nutritionist, together with advice from appropriate medical and sport science personnel, should be sought before adherence to a special diet.

\section{Acknowledgments}

D. M. Lis, E. Larson-Meyer, and D. Kings wrote initial draft of respective sections. D. M. Lis compiled, edited, formatted, and revised the manuscript. All authors approved the final version of the paper. The authors have no conflicts of interests to report.

\section{References}

Agnoli, C., Baroni, L., Bertini, I., Ciappellano, S., Fabbri, A., Papa, M., ... Sieri, S. (2017). Position paper on vegetarian diets from the working group of the Italian Society of Human Nutrition. Nutrition, Metabolism \& Cardiovascular Diseases, 27(12), 1037-1052. PubMed ID: 29174030 doi:10.1016/j.numecd.2017.10.020

Aird, T.P., Davies, R.W., \& Carson, B.P. (2018). Effects of fasted vs fed-state exercise on performance and post-exercise metabolism: A systematic review and meta-analysis. Scandinavian Journal of Medicine \& Science in Sports, 28(5), 1476-1493. PubMed ID: 29315892 doi:10.1111/sms.13054

Alkandari, J.R., Maughan, R.J., Roky, R., Aziz, A.R., \& Karli, U. (2012). The implications of Ramadan fasting for human health and wellbeing. Journal of Sports Sciences, 30(Suppl. 1), S9-S19. PubMed ID: 22742901 doi:10.1080/02640414.2012.698298

Aloui, A., Chtourou, H., Briki, W., Tabben, M., Chaouachi, A., Souissi, N., .. Chamari, K. (2016). Rapid weight loss in the context of Ramadan observance: Recommendations for judokas. Biology of Sport, 33(4), 407-413. PubMed ID: 28090146 doi:10.5604/ 20831862.1224098 
Applegate, C., Mueller, M., \& Zuniga, K.E. (2017). Influence of dietary acid load on exercise performance. International Journal of Sport Nutrition and Exercise Metabolism, 27(3), 213-219. PubMed ID: 28050921 doi:10.1123/ijsnem.2016-0186

Azizi, F. (2002). Research in Islamic fasting and health. Annals of Saudi Medicine, 22(3-4), 186-191. PubMed ID: 17159392 doi:10.5144/ 0256-4947.2002.186

Barkia, A., Mohamed, K., Smaoui, M., Zouari, N., Hammami, M., \& Nasri, M. (2011). Change of diet, plasma lipids, lipoproteins, and fatty acids during Ramadan: A controversial association of the considered Ramadan model with atherosclerosis risk. Journal of Health, Population and Nutrition, 29(5), 486-493. PubMed ID: 22106754 doi:10.3329/jhpn.v29i5.8902

Biesiekierski, J.R., \& Iven, J. (2015). Non-coeliac gluten sensitivity: Piecing the puzzle together. United European Gastroenterology Journal, 3(2), 160-165. PubMed ID: 25922675 doi:10.1177/ 2050640615578388

Bulka, C.M., Davis, M.A., Karagas, M.R., Ahsan, H., \& Argos, M. (2017). The unintended consequences of a gluten-free diet. Epidemiology, 28(3), e24-e25. PubMed ID: 28166100 doi:10.1097/EDE. 0000000000000640

Castell, L.M., Nieman, D., Bermon, S., \& Peeling, P. (2018). Exerciseinduced illness and inflammation: Can immunonutrition and iron help? International Journal of Sport Nutrition and Exercise Metabolism. Manuscript in preparation. 1-12.

Chamari, K., Briki, W., Farooq, A., Patrick, T., Belfekih, T., \& Herrera, C.P. (2016). Impact of Ramadan intermittent fasting on cognitive function in trained cyclists: A pilot study. Biology of Sport, 33(1), 49-56. PubMed ID: 26985134 doi:10.5604/20831862.1185888

Chtourou, H., Hammouda, O., Souissi, H., Chamari, K., Chaouachi, A., \& Souissi, N. (2011). The effect of Ramadan fasting on physical performances, mood state and perceived exertion in young footballers. Asian Journal of Sports Medicine, 2(3), 177-185. PubMed ID: 22375237 doi:10.5812/asjsm.34757

Cialdella-Kam, L., Kulpins, D., \& Manore, M.M. (2016). Vegetarian, gluten-free, and energy restricted diets in female athletes. Sports, 4(4), 1-12. PubMed ID: 29910298 doi:10.3390/sports4040050

Colbey, C., Cox, A.J., Pyne, D.B., Zhang, P., Cripps, A.W., \& West, N.P. (2018). Upper respiratory symptoms, gut health and mucosal immunity in athletes. Sports Medicine, 48(Suppl. 1), 65-77. PubMed ID: 29363055 doi:10.1007/s40279-017-0846-4

Costa, R.J.S., Snipe, R.M.J., Kitic, C.M., \& Gibson, P.R. (2017). Systematic review: Exercise-induced gastrointestinal syndrome-implications for health and intestinal disease. Alimentary Pharmacology \& Therapeutics, 46(3), 246-265. PubMed ID: 28589631 doi:10.1111/apt.14157

Craddock, J.C., Probst, Y.C., \& Peoples, G.E. (2016). Vegetarian and omnivorous nutrition-Comparing physical performance. International Journal of Sport Nutrition and Exercise Metabolism, 26(3), 212-220. PubMed ID: 26568522 doi:10.1123/ijsnem.2015-0231

de Silva, D., Geromi, M., Halken, S., Host, A., Panesar, S.S., Muraro, A., ... EAACI Food Allergy and Anaphylaxis Guidelines Group. (2014). Primary prevention of food allergy in children and adults: Systematic review. Allergy, 69(5), 581-589. PubMed ID: 24433563 doi:10.1111/all.12334

Fahrial Syam, A., Suryani Sobur, C., Abdullah, M., \& Makmun, D. (2016). Ramadan fasting decreases body fat but not protein mass. International Journal of Endocrinology and Metabolism, 14(1), e29687. PubMed ID: 27279831 doi:10.5812/ijem.29687

Farooq, A., Herrera, C.P., Zerguini, Y., Almudahka, F., \& Chamari, K. (2016). Knowledge, beliefs and attitudes of Muslim footballers towards Ramadan fasting during the London 2012 Olympics: a cross-sectional study. BMJ Open, 6(9), e012848
Fedewa, A., \& Rao, S.S. (2014). Dietary fructose intolerance, fructan intolerance and FODMAPs. Current Gastroenterology Reports, 16(1), 370. PubMed ID: 24357350 doi:10.1007/s11894-0130370-0

Gaskell, S.K., \& Costa, R.J.S. (2018). Applying a low-FODMAP dietary intervention to a female ultra-endurance runner with irritable bowel syndrome during a multi-stage ultra-marathon. International Journal of Sport Nutrition and Exercise Metabolism. Advance online publication. 1-7. PubMed ID: 29757053 doi:10.1123/ijsnem.2017-0398

Gibson, P.R., \& Muir, J.G. (2013). Not all effects of a gluten-free diet are due to removal of gluten. Gastroenterology, 145(3), 693. PubMed ID: 23900108 doi:10.1053/j.gastro.2013.06.056

Gibson, P.R., Muir, J.G., \& Newnham, E.D. (2015). Other dietary confounders: FODMAPS et al. Digestive Diseases, 33(2), 269-276. PubMed ID: 25925934 doi:10.1159/000371401

Gilani, G.S., Cockell, K.A., \& Sepehr, E. (2005). Effects of antinutritional factors on protein digestibility and amino acid availability in foods. Journal of AOAC International, 88(3), 967-987. PubMed ID: 16001874

Halmos, E.P., Christophersen, C.T., Bird, A.R., Shepherd, S.J., Gibson, P.R., \& Muir, J.G. (2015). Diets that differ in their FODMAP content alter the colonic luminal microenvironment. Gut, 64(1), 93-100. PubMed ID: 25016597 doi:10.1136/gutjnl-2014-307264

Heilbronn, L.K., Smith, S.R., Martin, C.K., Anton, S.D., \& Ravussin, E. (2005). Alternate-day fasting in nonobese subjects: Effects on body weight, body composition, and energy metabolism. The American Journal of Clinical Nutrition, 81(1), 69-73. PubMed ID: 15640462 doi:10.1093/ajen/81.1.69

Hill, P., Muir, J.G., \& Gibson, P.R. (2017). Controversies and recent developments of the low-FODMAP diet. Gastroenterology \& Hepatology, 13(1), 36-45. PubMed ID: 28420945

Horne, B.D., May, H.T., Anderson, J.L., Kfoury, A.G., Bailey, B.M., McClure, B.S., . . Intermountain Heart Collaborative Study. (2008). Usefulness of routine periodic fasting to lower risk of coronary artery disease in patients undergoing coronary angiography. The American Journal of Cardiology, 102(7), 814-819.e1. PubMed ID: 18805103 doi:10.1016/j.amjcard.2008.05.021

Jeromson, S., Gallagher, I.J., Galloway, S.D., \& Hamilton, D.L. (2015). Omega-3 fatty acids and skeletal muscle health. Marine Drugs, 13(11), 6977-7004. PubMed ID: 26610527 doi:10.3390/md13116977

Kirkendall, D.T., Chaouachi, A., Aziz, A.R., \& Chamari, K. (2012). Strategies for maintaining fitness and performance during Ramadan. Journal of Sports Sciences, 30(Suppl. 1), S103-S108. PubMed ID: 22606971 doi:10.1080/02640414.2012.687114

Kostic-Vucicevic, M., Marinkovi, D., Dikic, N., Stojmenovic, T., Andjelkovic, M., Nikolic, I., ... Malic, T. (2016). Is there connection between food intolerance and sports performance in elite athletes? British Journal of Sports Medicine, 50, A20. doi:10.1136/bjsports2016-097120.35

Krajcovicova-Kudlackova, M., Buckova, K., Klimes, I., \& Sebokova, E. (2003). Iodine deficiency in vegetarians and vegans. Annals of Nutrition \& Metabolism, 47(5), 183-185. PubMed ID: 12748410 doi:10.1159/000070483

Larson-Meyer, D.E. (2018). Optimizing performance on a vegetarian diet. In W. Craig (Ed.), Vegetarian nutrition and wellness (pp. 303-319). New York, NY: CRC Press.

Leahy, E., Lyons, S., \& Tol, S.J. (2010). An estimate of the number of vegetarians in the world (pp. 1-44). Dublin, Ireland: ESRI. https:// www.researchgate.net/publication/254412281_An_Estimate_of_the_ Number_of_Vegetarians_in_the_World

Levitt, M., Wilt, T., \& Shaukat, A. (2013). Clinical implications of lactose malabsorption versus lactose intolerance. Journal of Clinical 
Gastroenterology, 47(6), 471-480. PubMed ID: 23632346 doi:10. 1097/MCG.0b013e3182889f0f

Lis, D., Ahuja, K.D., Stellingwerff, T., Kitic, C.M., \& Fell, J. (2016a). Case study: Utilizing a low FODMAP diet to combat exerciseinduced gastrointestinal symptoms. International Journal of Sport Nutrition and Exercise Metabolism, 26(5), 481-487. PubMed ID: 27097380 doi:10.1123/ijsnem.2015-0293

Lis, D., Ahuja, K.D., Stellingwerff, T., Kitic, C.M., \& Fell, J. (2016b). Food avoidance in athletes: FODMAP foods on the list. Applied Physiology, Nutrition, and Metabolism, 41(9), 1002-1004. PubMed ID: 27507006 doi:10.1139/apnm-2015-0428

Lis, D., Stellingwerff, T., Kitic, C.M., Ahuja, K.D., \& Fell, J. (2015a). No effects of a short-term gluten-free diet on performance in nonceliac athletes. Medicine \& Science in Sports \& Exercise, 47(12), 2563-2570. PubMed ID: 25970665 doi:10.1249/MSS.0000000 000000699

Lis, D., Stellingwerff, T., Kitic, C.M., Fell, J.W., \& Ahuja, K.D.K. (2017). Low FODMAP: A preliminary strategy to reduce gastrointestinal distress in athletes. Medicine \& Science in Sports \& Exercise, 50(1), 116-123. PubMed ID: 28891824 doi:10.1249/MSS.0000000 000001419

Lis, D., Stellingwerff, T., Shing, C.M., Ahuja, K.D., \& Fell, J. (2015b). Exploring the popularity, experiences, and beliefs surrounding gluten-free diets in nonceliac athletes. International Journal of Sport Nutrition and Exercise Metabolism, 25, 37-45. PubMed ID: 24901744 doi:10.1123/ijsnem.2013-0247

Marsh, K.A., Munn, E.A., \& Baines, S.K. (2013). Protein and vegetarian diets. The Medical Journal of Australia, 199(Suppl. 4), S7-S10. PubMed ID: 25369930

Masuy, I., Van Oudenhove, L., Tack, J., \& Biesiekierski, J.R. (2018). Effect of intragastric FODMAP infusion on upper gastrointestinal motility, gastrointestinal, and psychological symptoms in irritable bowel syndrome vs healthy controls. Neurogastroenterology \& Motility, 30(1). PubMed ID: 28762592 doi:10.1111/nmo.13167

Maughan, R.J., Al-Kharusi, W., Binnett, M.S., Budgett, R., Burke, L.M., Coyle, E.F., ... Vennard, P. (2012). Fasting and sports: A summary statement of the IOC workshop. British Journal of Sports Medicine, 46(7), 457-457. PubMed ID: 21112876 doi:10.1136/bjsm.2010. 073064

Maughan, R.J., Burke, L.M., Dvorak, J., Larson-Meyer, D.E., Peeling, P., Phillips, S.M., . . Engebretsen, L. (2018). IOC consensus statement: Dietary supplements and the high-performance athlete. British Journal of Sports Medicine, 52(7), 439-455. PubMed ID: 29540367 doi:10.1136/bjsports-2018-099027

Maughan, R.J., Fallah, J., \& Coyle, E.F. (2010). The effects of fasting on metabolism and performance. British Journal of Sports Medicine, 44(7), 490-494. PubMed ID: 20484315 doi:10.1136/bjsm.2010. 072181

Meckel, Y., Ismaeel, A., \& Eliakim, A. (2008). The effect of the Ramadan fast on physical performance and dietary habits in adolescent soccer players. European Journal of Applied Physiology, 102(6), 651-657. PubMed ID: 18071743 doi:10.1007/s00421-0070633-2

Melina, V., Craig, W., \& Levin, S. (2016). Position of the Academy of Nutrition and Dietetics: Vegetarian diets. Journal of the Academy of Nutrition and Dietetics, 116(12), 1970-1980. PubMed ID: 27886704 doi:10.1016/j.jand.2016.09.025

Memari, A.H., Kordi, R., Panahi, N., Nikookar, L.R., Abdollahi, M., \& Akbarnejad, A. (2011). Effect of Ramadan fasting on body composition and physical performance in female athletes. Asian Journal of Sports Medicine, 2(3), 161-166. PubMed ID: 22375235 doi:10.5812/ asjsm. 34754
Messina, M., \& Redmond, G. (2006). Effects of soy protein and soybean isoflavones on thyroid function in healthy adults and hypothyroid patients: A review of the relevant literature. Thyroid, 16(3), 249-258. PubMed ID: 16571087 doi:10.1089/thy.2006.16.249

Meyer, N., \& Reguant-Closa, A. (2017). "Eat as if you could save the planet and win!" Sustainability integration into nutrition for exercise and sport. Nutrients, 9(4), 412. PubMed ID: 28430140 doi:10.3390/ nu9040412

Moro, T., Tinsely, G., Bianco, A., Marcolin, G., Pacelli, Q.F., Battaglia, G., ... Paoli, A. (2016). Effects of eight weeks of time-restricted feeding on basal metabolism, maximal strength, body composition, inflammation, and cardiovascular risk factors in resistance-trained males. Journal of Translational Medicine, 14(1), 290. PubMed ID: 27737674 doi:10.1186/s12967-016-1044-0

Morton, J., Stellingwerff, T., \& Burke, L.M. (2018). Periodised nutrition for training adaptation. International Journal of Sport Nutrition and Exercise Metabolism. Manuscript in preparation.

Mountjoy, M., Sundgot-Borgen, J.K., Burke, L.M., Ackerman, K.E., Blauwet, C., Constantini, N., . . Budgett, R. (2018). IOC consensus statement on relative energy deficiency in sport (RED-S): 2018 update. British Journal of Sports Medicine, 52(11), 687-697. PubMed ID: 29773536 doi:10.1136/bjsports-2018-099193

Norouzy, A., Salehi, M., Philippou, E., Arabi, H., Shiva, F., Mehrnoosh, S., \& Nematy, M. (2013). Effect of fasting in Ramadan on body composition and nutritional intake: A prospective study. Journal of Human Nutrition and Dietetics, 26(Suppl. 1), 97-104. PubMed ID: 23679071 doi:10.1111/jhn.12042

Ong, D.K., Mitchell, S.B., Barrett, J.S., Shepherd, S.J., Irving, P.M., Biesiekierski, J.R., . . Muir, J.G. (2010). Manipulation of dietary short chain carbohydrates alters the pattern of gas production and genesis of symptoms in irritable bowel syndrome. Journal of Gastroenterology and Hepatology, 25(8), 1366-1373. PubMed ID: 20659225 doi:10.1111/j.1440-1746.2010.06370.x

Otten, J.J., Hellwig, J.P., \& Meyers, L.D. (2006). The dietary reference intakes: The essential guide to nutrient requirements. Washington, DC: Food and Nutrition Board, Institute of Medicine.

Owens, D.J., Allison, R., \& Close, G.L. (2018). Vitamin D and the athlete: Current perspectives and new challenges. Sports Medicine, 48(Suppl. 1), 3-16. PubMed ID: 29368183 doi:10.1007/s40279-0170841-9

Pelly, F.E., \& Burkhart, S.J. (2014). Dietary regimens of athletes competing at the Delhi 2010 Commonwealth Games. International Journal of Sport Nutrition and Exercise Metabolism, 24(1), 28-36. PubMed ID: 23918635 doi:10.1123/ijsnem.2013-0023

Pfeiffer, B., Stellingwerff, T., Hodgson, A.B., Randell, R., Pöttgen, K., Res, P., \& Jeukendrup, A.E. (2012). Nutritional intake and gastrointestinal problems during competitive endurance events. Medicine \& Science in Sports \& Exercise, 44(2), 344-351. PubMed ID: 21775906 doi:10.1249/MSS.0b013e31822dc809

Platt, M.P., \& Wulu, J.A. (2017). Rational approach to allergy testing. Otolaryngologic Clinics of North America, 50(6), 1103-1110. PubMed ID: 29103452 doi:10.1016/j.otc.2017.08.007

Reilly, T., \& Waterhouse, J. (2007). Altered sleep-wake cycles and food intake: The Ramadan model. Physiology \& Behavior, 90(2-3), 219-228. PubMed ID: 17081572 doi:10.1016/j.physbeh.2006. 09.004

Roky, R., Houti, L., Houssamih, S., Qotbi, S., \& Aadil, N. (2004). Diurnal variation in temperature, mental and physical performance, and tasks specifically related to football. Chronobiology International, 48(4), 296-303.

Rona, R.J., Keil, T., Summers, C., Gislason, D., Zuidmeer, L., Sodergren, E., ... Madsen, C. (2007). The prevalence of food allergy: A meta- 
analysis. The Journal of Allergy and Clinical Immunology, 120(3), 638-646. PubMed ID: 17628647 doi:10.1016/j.jaci.2007. 05.026

Sapone, A., Bai, J.C., Ciacci, C., Dolinsek, J., Green, P.H., Hadjivassiliou, M., ... Fasano, A. (2012). Spectrum of gluten-related disorders: Consensus on new nomenclature and classification. BMC Medicine, 10, 13. PubMed ID: 22313950 doi:10.1186/1741-7015-10-13

Schafer, T., Bohler, E., Ruhdorfer, S., Weigl, L., Wessner, D., Heinrich, J., ... Ring, J. (2001). Epidemiology of food allergy/food intolerance in adults: Associations with other manifestations of atopy. Allergy, 56(12), 1172-1179. PubMed ID: 11736746 doi:10.1034/j.13989995.2001.00196.x

Shepherd, S.J., \& Gibson, P.R. (2013). Nutritional inadequacies of the gluten-free diet in both recently-diagnosed and long-term patients with coeliac disease. Journal of Human Nutrition and Dietetics. 26(4), 349-358. PubMed ID: 23198728 doi:10.1111/jhn.12018

Shtessel, M., \& Tversky, J. (2018). Reliability of allergy skin testing. Annals of Allergy, Asthma \& Immunology, 120(1), 80-83. PubMed ID: 29273134 doi:10.1016/j.anai.2017.10.015

Skodje, G.I., Sarna, V.K., Minelle, I.H., Rolfsen, K.L., Muir, J.G., Gibson, P.R., ... Lundin, K.E.A. (2018). Fructan, rather than gluten, induces symptoms in patients with self-reported non-celiac gluten sensitivity. Gastroenterology, 154(3), 529-539.e2. PubMed ID: 29102613 doi:10.1053/j.gastro.2017.10.040

Staudacher, H.M., Irving, P.M., Lomer, M.C., \& Whelan, K. (2014). Mechanisms and efficacy of dietary FODMAP restriction in IBS. Nature Reviews Gastroenterology \& Hepatology, 11(4), 256-266. PubMed ID: 24445613 doi:10.1038/nrgastro.2013.259

Staudacher, H.M., Lomer, M.C.E., Farquharson, F.M., Louis, P., Fava, F., Franciosi, E., ... Whelan, K. (2017). A diet low in FODMAPs reduces symptoms in patients with irritable bowel syndrome and a probiotic restores bifidobacterium species: A randomized controlled trial. Gastroenterology, 153(4), 936-947. PubMed ID: 28625832 doi:10.1053/j.gastro.2017.06.010
Stockman, M.C., Thomas, D., Burke, J., \& Apovian, C.M. (2018). Intermittent fasting: Is the wait worth the weight? Current Obesity Reports, 7(2), 172-185. PubMed ID: 29700718 doi:10.1007/s13679018-0308-9

Tapke, D.E., Scherzer, R., \& Grayson, M.H. (2018). Unnecessary food allergy testing by primary care providers: Ethical implications for the specialist. Annals of Allergy, Asthma \& Immunology,121(6), 668-672. PubMed ID: 30009878 doi:10.1016/j.anai.2018.07.009

Tian, H.H., Aziz, A.R., Png, W., Wahid, M.F., Yeo, D., \& Constance Png, A.L. (2011). Effects of fasting during Ramadan month on cognitive function in Muslim athletes. Asian Journal of Sports Medicine, 2(3), 145-153. PubMed ID: 22375233 doi:10.5812/asjsm.34753

Tinsley, G., Forsse, J., Butler, N., Paoli, A., \& Bane, A. (2017). Timerestricted feeding in young men performing resistance training: A randomized controlled trial. European Journal of Sport Science, 17(2), 200-207. PubMed ID: 27550719 doi:10.1080/17461391. 2016.1223173

Trapp, D., Knez, W., \& Sinclair, W. (2010). Could a vegetarian diet reduce exercise-induced oxidative stress? A review of the literature. Journal of Sports Sciences, 28(12), 1261-1268. PubMed ID: 20845212 doi:10.1080/02640414.2010.507676

Trepanowski, J., \& Bloomer, R. (2010). The impact of religious fasting on human health. Nutrition Journal, 9, 57. PubMed ID: 21092212 doi:10.1186/1475-2891-9-57

Turnbull, J.L., Adams, H.N., \& Gorard, D.A. (2015). Review article: The diagnosis and management of food allergy and food intolerances. Alimentary Pharmacology \& Therapeutics, 41(1), 3-25. PubMed ID: 25316115 doi:10.1111/apt.12984

van Wijck, K., Lenaerts, K., Grootjans, J., Wijnands, K.A., Poeze, M., van Loon, L.J., ... Buurman, W.A. (2012). Physiology and pathophysiology of splanchnic hypoperfusion and intestinal injury during exercise: Strategies for evaluation and prevention. American Journal of Physiology. Gastrointestinal and Liver Physiology, 303(2), G155-G168. PubMed ID: 22517770 doi:10.1152/ajpgi.00066.2012 